\title{
Collaborating to Deliver Value in Health Care: Exploring conditions required for successful Healthcare and Life Science Sector Collaboration
}

\author{
Daniel J Rees ${ }^{l}$, Victoria Bates ${ }^{1,2}$, Roderick Thomas ${ }^{1}$, Simon B. Brooks ${ }^{1}$, Leighton Phillips, \\ Hamish Laing ${ }^{l}$, Gareth Davies ${ }^{l}$, Michael D. Williams ${ }^{l}$ and Yogesh K. Dwivedi ${ }^{1 *}$ \\ ${ }^{1}$ School of Management, Swansea University, Swansea, SA1 8EN, UK, \\ ${ }^{2}$ Pfizer UK, Tadworth KT20 7NS, UK \\ Emails: D.J.Rees@Swansea.ac.uk; victoria.bates@swansea.ac.uk; \\ roderick.a.thomas@swansea.ac.uk; s.b.brooks@swansea.ac.uk; L.Phillips@Swansea.ac.uk; \\ Hamish.Laing@Swansea.ac.uk; g.h.davies@swansea.ac.uk; m.d.williams@swansea.ac.uk; \\ ykdwivedi@gmail.com
}

\section{Acknowledgements}

Victoria Bates is seconded to Swansea University School of Management as ValueBased Healthcare and Industry Director. The position is jointly supported by Pfizer UK and Swansea University School of Management. Professor Hamish Laing holds a position at Swansea University School of Management which is funded by Pfizer.

\begin{abstract}
Purpose: The UK Government-funded National Health Service (NHS) is experiencing significant pressures owing to the complexity of challenges to, and demands of, healthcare provision. This situation has driven government policy level support for transformational change initiatives, such as Value-Based Health Care (VBHC), through closer alignment and collaboration across the healthcare system-life science sector nexus.

The purpose of this paper is to evaluate the necessary antecedents to collaboration in VBHC through a critical exploration of the existing literature, with a view to establishing the foundations for further development of policy, practice and theory in this field
\end{abstract}

Design/methodology/approach: A literature review was conducted via searches on Scopus and Google Scholar between 2009-2019 for peer-reviewed articles containing keywords and phrases 'Value-based healthcare industry' and 'healthcare industry collaboration'. Refinement of the results led to the identification of 'guiding conditions' for collaboration in VBHC.

Findings: Five literature-derived guiding conditions (GCs) were identified as necessary for the successful implementation of initiatives such as VBHC through system-sector collaboration. These are: a multi-disciplinarity; use of appropriate technological infrastructure; capturing meaningful metrics; understanding the total cycle-of-care; financial flexibility. The paper outlines research opportunities to empirically test the relevance of the five GCs with regard to improving system-sector collaboration on VBHC.

* Corresponding Author 
Originality/value: The paper has developed a practical and constructive framework that has the potential to inform both policy and further theoretical development on collaboration in VBHC.

Keywords: Healthcare, Government, Management, Process, VBHC, Innovation, Life Science Sector, Organization, Industry, Policy, NHS.

Paper Type: Conceptual Paper

\section{Introduction}

The National Health Service (NHS) in the UK, in common with other national healthcare systems, is facing significant challenges in managing the demands associated with an aging population with increasingly complex needs, higher workforce and technology costs, and financial constraints (Pilemalm, Lindgren, \& Ramsell, 2016). Despite increasing government investment in recent years, projected demands continue to outstrip the resources available to meet them (The Kings Fund, 2019). It should additionally be noted that the NHS is significantly devolved to regional authorities and semi-autonomous local trusts, with complex mechanisms of regulation and funding (Crocker, Johnson, \& King, 2009).

Under such conditions, optimisation of service delivery with constrained resources and adherence to performance measures requires a careful balance (Chahal \& Eldabi, 2011). The possibility and efficiency of the 'healthcare and life science collaboration' are a function of the existing regulatory frameworks and an overall logic that drives a government's scope and modes of involvement in the economy. As such, the examination of the healthcare-life science nexus, as exemplified by government-funded NHS and private sector, offers a useful insight into the issues and relationships between healthcare external organisations (Ferlie \& McGivern, 2003). Since then Government policy documents have recognised that closer alignment between healthcare system and private life science sector companies is required to stem the growing challenges of healthcare provision (Gov UK (OLS), 2017; Gov UK, 2017; WAG, 2018). One approach which is gathering momentum is Value-Based Health Care (VBHC); a mechanism through which it is theoretically possible to by provide better value personal, social, technical, and allocative value in healthcare provision for the resource spent (EXPH, 2019; M. Gray, 2017a).

The overarching objective of this paper is to explore and evaluate the necessary antecedents for system-sector collaboration with a view of establishing foundations for the future development of policy, practise and theory in the field of VBHC. As part of this study this paper examines the concept of VBHC as a potential means of addressing these complex challenges in the UK context, with particular consideration given to the importance of collaboration between the healthcare system and the life-sciences sector. One of the aims of the study is to explore the varying definitions of VBHC, and consequently a definition is not offered as a foundation in this introduction. However, VBHC could essentially be described as focusing on the investment of resources where they are most likely to deliver outcomes that matter most to patients. 
The next section of the paper therefore traces the development of VBHC from the work of (among others) Porter and Teisberg $(2004 ; 2006)$ in the United States (US). In addition, the emerging understanding of VBHC is explored from a European and UK perspective. This section also explores the complex UK context that is arguably driving the need for VBHC, as well as introducing the importance of collaboration between the healthcare system and the life-sciences sector.

Following this, the methodology of the study is briefly set out, before the main findings of the paper are presented and discussed. The study reviewed the literature on VBHC and has identified five key 'guiding conditions' which are hypothesised as critical success factors in the implementation of VBHC through collaboration between the healthcare system (henceforth 'system') and the life science sector (henceforth 'sector').

The overall objective and purpose of this paper is to evaluate the necessary antecedents to collaboration in VBHC In doing so we make three main contributions Firstly, the paper evaluates the concept of VBHC from a specifically UK perspective, relating it to this context and proposing a nuanced characterisation to augment the US-based origins of VBHC. Secondly, the study surfaces those high-level guiding conditions necessary for successful system-sector collaboration. Finally, a research agenda is proposed that offers prospects for further contributions to policy, practice and theory in VBHC. Critical exploration of the existing literature in this study sets foundations for development of practical and constructive framework through empirical research.

Before proceeding to a more detailed exploration of VBHC in the next section, it is important to be clear what is meant by both 'healthcare system' and 'life sciences sector' in this paper. A 'healthcare system' has been defined by World Health Organisation (WHO) as all the activities whose primary purpose is to promote, restore or maintain health (WHO, 2009). This includes both the physical infrastructure, processes and systems involved in providing a range of services to patients, and the health workforce or healthcare providers concerned with delivering outcomes to patients. The life sciences sector in this paper refers to the biopharmaceutical and medical technology companies involved in medicine development and areas such as genetics-based and personalised healthcare, social media technologies, information and communications technologies, data science and machine learning/artificial intelligence (Gov UK, 2018a).

\section{Value-Based Healthcare}

\section{Defining value-based healthcare}

The concept of VBHC is generally considered to have originated through the work of Michael Porter and Elizabeth Teisberg at Harvard Business School at the start of this century (Porter and Teisberg, 2004). They argued that the (then) current state of competition in US Healthcare was a source of value destruction, or at least zero-sum outcomes, rather than creating value for patients (Porter and Teisberg, 2004). This work formed the basis of a subsequent book (Porter and Teisberg, 2006) which emphasised the language of 'value' more than in earlier work, hence the contemporary label, 'Value-Based Healthcare'. Porter is of course very closely associated with the notion of 'value' from his work on value chains and value systems in the field of strategy, through to later publications on 'creating shared value' (see for example Porter 1985; Porter and Kramer, 2011). 
The original definition of VBHC proposed by Porter and Teisberg (2006), has gained traction:

"Patient value is defined as patient-relevant outcomes, divided by the costs per patient across the full cycle of care in order to achieve these outcomes. ValueBased Healthcare focuses on maximising the value of care for patients and reducing the cost of healthcare."

(Porter and Teisberg, 2006)

This was further discussed by Porter and Lee (2013) emphasising the key objective for providers of healthcare organisations:

"In health care, the overarching goal for providers, as well as for every other stakeholder, must be improving value for patients, where value is defined as the health outcomes achieved that matter to patients relative to the cost of achieving those outcomes."

(Porter and Lee, 2013, p.4)

The US-based literature, which is largely derived from Porter and his collaborators, focuses on cost-restraint objectives and tackling allocative efficiency, productive efficiency and outcome-based contracting. There are variations on the definition of VBHC, but the dominant theme remains the shift from supply-driven systems orchestrated around clinical activity, towards a patient-driven system where provider-defined outcomes or quality indicators are delivered to patients and are costed to derive 'value'.

Porter's work is based in the US context, while the European view of VBHC is arguably a broader interpretation extending beyond individual patient value to consider societal impact, available resource and equitable distribution. See for example the following definition from The European Commission Expert Panel on Effective Ways of Investing in Health (EXPH):

'...a comprehensive concept built on four value-pillars: appropriate care to achieve patients' personal goals (personal value), achievement of best possible outcomes with available resources (technical value), equitable resource distribution across all patient groups (allocative value) and contribution of healthcare to social participation and connectedness (societal value).'

(EXPH, 2019, p.5)

While acknowledging that different stakeholders will potentially have different perceptions of how value is defined, they also stated that:

"...value-based health systems are seen by some as a system change which could improve the quality of healthcare for patients, while simultaneously making healthcare more cost-effective."

(EXPH, 2019, p. 9)

The next sub-section now explores the context within which VBHC is beginning to be implemented, highlighting the strategic drivers for VBHC and thereby arguing for the importance of system-sector collaboration. 
A complex and interwoven array of economic, political, technological and demographic change-drivers impact on both healthcare systems and the life sciences sector in the UK and beyond (Deloitte, 2018).

Economically, the evolving situation is concerning for the UK government and decision makers at devolved governments who decide how they wish to fund their healthcare system. Global spending growth on healthcare increased at an annual rate of $1.3 \%$ from 2012-2016 rising to a projected 4.1\% between 2017 and 2021 (Deloitte, 2018). The increase is driven by factors including ageing population, increasing population, advances in medical treatments, and rising labour cost (EIU, 2016a). In the UK, healthcare spending has increased at a faster rate than inflation and GDP, accounting for $7.3 \%$ of national income in year 2018/19 (Charlesworth et al., 2018). Increased spending by NHS England is projected to increase by an average of 3.3\% a year between 2018-19 and 2033-34, translating to a real-term increase in spending from $£ 128$ billion to $£ 210$ billion (Charlesworth et al., 2018).

Despite such expenditure, efficiencies are hard to derive (Berwick \& Hackbarth, 2012). The OECD report on "Wasteful Spending in Health" (OECD, 2017) presented data on inappropriate care and wasted resources with estimations ranging from a conservative $10 \%$ up to $34 \%$ of expenditure.

Politically, the challenges facing healthcare systems in the UK has been noted at a national (Gov UK, 2017) and devolved Government (WAG, 2018) level. There is growing recognition of active NHS engagement with stakeholders and organisations in the life science sector, to enable transformation in the way UK healthcare is delivered (Gov UK, 2017). This is accompanied by a policy drive towards more effective system-sector collaboration as a mechanism by which it is possible to address the mounting healthcare challenges through adoption and implementation of VBHC.

Technologically, research, development and adoption are driving a paradigm shift towards delivering patient experience improvements. (Charlesworth, Watt, \& Johnson, 2018). The annual spend on R\&D in the English NHS, inclusive of that spent through National Institute for Health Research (NIHR) totalled £1.2bn between the years 2014 and 2015; and the approximate annual spend on facilitating the adoption and spread of innovation in the NHS through Academic Health Science Networks (AHSNs) was £50m between 2013 and 2018 (Charlesworth et al., 2018).

Economic pressure and growing demand from patients lead to policymakers exploring alternative means to manage healthcare budgets (EIU, 2016b). This coupled with the challenges to continue to adopt innovation in medicines and services provided by the NHS requires a step-change towards moving from volume to value in delivering sustainable healthcare.

These various drivers, of which these are a sample, are leading to increased emphasis on the need for transformational change, as the following quotes reinforce: 
"We've got to break down barriers and build long-term, focussed, collaborative relationships where our incentives are aligned, so if you win, we win; if you lose, we lose."

(Porter \& Ishrak, 2015, p. 6)

"There are a lot of opportunities for reduced costs, and I think medical technology companies can play a big role"

(Porter \& Ishrak, 2015, p. 4)

'The historical model where innovators simply throw new products at health systems and allow them to layer these into existing pathways is no longer viable.'

Professor Sir John Bell (Gov UK, 2016, p. 7).

Policy makers have begun to respond to these strategic pressures to seek closer systemsector alignment to reward the sector for delivery of outcomes to patients. Initiatives such as value-based and 'Prudent' healthcare are highlighted in both the UK Life Sciences Strategy (Gov UK, 2017) and A Healthier Wales (WAG, 2018) respectively, both alluding to system-sector collaboration. Proposed areas for collaboration include:

(1) Risk-sharing with respect to development of tools and therapies using NHS infrastructure to run iterative evaluation studies with the aim of benefit sharing from proven technologies;

(2) collaborative re-shaping clinical pathways to improve efficiencies and patient throughput activity;

(3) Collection of real-world data and linking this to assess clinical and costeffectiveness

(Gov UK, 2018a).

While collaboration arguably remains sporadic and fragmented, there are a number of instances of fruitful system-sector collaboration. For example, AstraZeneca and Leeds Teaching Hospital engaged in a partnership focused on reviewing heart disease patients' medication, leading to a fall in acute coronary syndrome readmissions by approximately $50 \%$ (AstraZeneca, 2018). A further example is the work of Medtronic Integrated Health Solutions partnering with a range of NHS hospital trusts in England to provide and manage catheterisation laboratories, resulting in significant operational efficiencies (Deloitte, 2019).

This section has introduced the concept of VBHC and traced its development form its US origins to the beginnings of implementation in the UK context today. The argument has been presented that the adoption of system-sector collaboration for VBHC can lead to fundamental transformation to improve healthcare delivery through investing in best value for the population (allocative efficiency); ensuring the best value in clinical pathways (productive efficiency); and deliver the best value when procuring services, medical devices and medicines (outcome-based contracting). The paper now moves on to briefly set out the methodology before presenting and discussing the findings.

\section{Methodology}


The research design for this paper was based on a structured literature search and an iterative content analysis. The literature included peer reviewed journal articles as well as government reports and policy statements and so on.

The initial literature search was conducted through the Scopus Catalogue up to 2019, seeking peer reviewed articles, using key words "value-based healthcare industry drugs medications"; "Value-based Healthcare Industry Healthcare Collaboration"; "collaboration Value-based Healthcare". This initial search generated over 8,900 articles.

These articles were reviewed manually for the 200 most relevant based on titles of the articles and the abstracts.

Based on a methodology for identifying factors from extant literature used by Bacon, Williams, \& Davies, 2019 a total of 63 of these articles were reviewed in detail. Any guiding condition for the successful collaborative implementation of VBHC found in more than ten of these articles was included for further exploration.

The authors then used the same key words in public search engines such as 'Google'. This was used alongside references from the 200 papers to identify relevant literature and reports from Government and consultant groups, online reports, articles and case studies relevant to the implementation of VBHC and system-sector collaboration. Relevance was determined by iterative manual viewing of literature content and it being inclusive of contextual information surrounding system and sector collaboration.

Used jointly, these methods of data collection and analysis allowed multiple perspectives to be gleaned on the implementation of VBHC with particular emphasis on collaboration between elements of the healthcare system and the life sciences sector. The next section of the paper now sets out and discusses the five guiding conditions derived from the literature search.

\section{Guiding conditions for system-sector collaboration for implementation of in value- based health care}

One of the main contributions of this paper lies in identifying which conditions are proposed to be significant conditions to facilitate successful system-sector collaboration in VBHC. The resulting guiding conditions, their general characteristics derived from the literature search and the linked references are summarised in Table 1 below. 
Table1. Characteristics Underpinning Guiding Conditions and Linked Citations

\begin{tabular}{|c|c|c|}
\hline $\begin{array}{c}\text { Guiding } \\
\text { Condition }\end{array}$ & Key Characteristics derived from the literature & Citations \\
\hline $\begin{array}{l}\text { A Multi- } \\
\text { disciplinary } \\
\text { Approach }\end{array}$ & $\begin{array}{l}\text { Collaboration between all stakeholders; Multi- } \\
\text { disciplinary; organization from across the System, } \\
\text { patients, patient advocates and private sector; a } \\
\text { team-in-lead strategy; public-private partnerships; } \\
\text { spectrum of healthcare providers; multi-sector } \\
\text { engagement; integrated care delivery systems; } \\
\text { collaboration with physicians, hospital systems; } \\
\text { work together and to each-others strengths; all } \\
\text { stakeholders to engage with medical device } \\
\text { industry; new relationships with industry }\end{array}$ & $\begin{array}{l}\text { (Hara } \text { et al., 2003); (VBHC Center Europe, 2019); } \\
\text { (Horne et al., 2019); (Malik et al., 2018); (Nishtar, } \\
\text { 2004); (Porter et al., 2013); (Beck et al., 2012); } \\
\text { (Kaplan \& Babad, 2011); (Zelmer, 2018); (Nilsson } \\
\text { et al., 2017); (Gerecke et al., 2015); (Dafny et al., } \\
\text { 2016); (Porter \& Ishrak, 2015); (Medtronic, 2016); } \\
\text { (Gov UK, 2016); (Martschinke \& Traut, 2016); (Hu } \\
\text { et al., 2000); (WAG, 2018); (EIU, 2016b); (Young } \\
\text { et al., 2001); (Hurh, Ko, \& Lee, 2017); (Handke } \text { et } \\
\text { al., 2017); (Lewis, 2019) }\end{array}$ \\
\hline $\begin{array}{l}\text { Meaningful } \\
\text { Metrics and } \\
\text { Measurements }\end{array}$ & $\begin{array}{l}\text { Most appropriate feasible measures; ICHOM set; } \\
\text { Patient Reported Outcomes PROMS; measure } \\
\text { quality and cost indicators across full care cycle } \\
\text { of patient care; provide real-time data; connect } \\
\text { and analyse accurate quality and financial data; } \\
\text { costing and informatics expertise; patient's } \\
\text { outcome and true cost, performance measurement; } \\
\text { public reporting of quality measures; analyse } \\
\text { outcomes and costs holistically; total costs of } \\
\text { patient's medical condition; consensus-based } \\
\text { patient-centric outcome measures. }\end{array}$ & $\begin{array}{l}\text { (VBHC Center Europe, 2019); (Chapman, 2014); } \\
\text { (ICHOM, 2015); (Lee, 2010); (Porter et al., 2013); } \\
\text { (Beck et al., 2012); (Aneurin Bevan University } \\
\text { Health Board, 2019); (Kavanagh } \text { et al., 2012); } \\
\text { (Porter \& Lee, 2013); (Handke et al.., 2017); (Porter } \\
\text { \& Ishrak, 2015); (Neumann et al., 2011); (Wang et } \\
\text { al., 2009); (Doyle, 2011); (Martschinke \& Traut, } \\
\text { 2016); (Miller, 2012); (Nilsson et al., 2017); (WAG } \\
\text { 2018); (EIU, 2016b); (Jönsson, 2009). }\end{array}$ \\
\hline $\begin{array}{l}\text { Utilisation of } \\
\text { Robust } \\
\text { Infrastructure } \\
\text { and } \\
\text { Technological } \\
\text { Platforms }\end{array}$ & $\begin{array}{l}\text { Infrastructure; Technologies; solving the data } \\
\text { extraction gap; effective health information } \\
\text { system; patient-centred mobile infrastructure; } \\
\text { telepresence technology; build and enable } \\
\text { information technology platforms; digital } \\
\text { infrastructure to capture information; technology } \\
\text { systems; health data infrastructure }\end{array}$ & $\begin{array}{l}\text { (Hara } \text { et al., 2003); (Patel, Pettitt, \& Wilson, 2012); } \\
\text { (Deloitte, 2018); (VBHC Center Europe, 2019); } \\
\text { (Nishtar, 2004); (Chapman, 2014); (Beck et al., } \\
\text { 2012); (Porter \& Ishrak, 2015); (Gov UK, 2016); } \\
\text { (Kotzbauer \& Weeks, 2015); (Neumann } \text { et al., 2011 } \\
\text {; (Carlson } \text { et al., 2010); (Ford \& Hughes, 2007); } \\
\text { (EIU, 2016b); (Hurh } \text { et al., 2017). }\end{array}$ \\
\hline $\begin{array}{l}\text { Knowledge of } \\
\text { the Total } \\
\text { Cycle of Care }\end{array}$ & $\begin{array}{l}\text { Whole cycle of patients care; full cycle of care; } \\
\text { total life-cycle; complete cycle of care; full care } \\
\text { pathway; quality cycle affecting whole system } \\
\text { pathways; entire care continuum; complete } \\
\text { pathway of disease. }\end{array}$ & $\begin{array}{c}\text { (Kaplan \& Porter, 2011); (ICHOM, 2015); } \\
\text { (Moxham, 2018); (Porter et al., 2013); (Porter \& } \\
\text { Lee, 2013); (Gerecke et al., 2015); (Keel } \text { et al., } \\
\text { 2017); (WAG, 2018); (Deerberg-Wittram et al., } \\
\text { 2017); (Verbeek \& Lord, 2007). }\end{array}$ \\
\hline $\begin{array}{l}\text { Financial } \\
\text { Flexibility }\end{array}$ & $\begin{array}{l}\text { Bundle Payments for Care Improvements (BPCI); } \\
\text { adequate resources (finance, time, physical space, } \\
\text { equipment, tools and personnel); flexibility; } \\
\text { contract and risk management; new business } \\
\text { models that align financial incentives; modify } \\
\text { financial model to bundle reimbursement; access } \\
\text { to required capital finance; value-based } \\
\text { purchasing; new financial models; risk-sharing } \\
\text { agreements to link payment for drugs to health } \\
\text { outcomes; flexible reimbursement system; in- } \\
\text { flexible cost-based reimbursements is a barrier; } \\
\text { performance-based reimbursement schemes; data } \\
\text { informed investment/disinvestment. }\end{array}$ & $\begin{array}{c}\text { (Hardin et al, 2017); (Mills \& Kanavos, 2019); } \\
\text { (EIU, 2016b); (Gerecke et al, 2015); (Robinson et } \\
\text { al, 2018); (Lewis, 2019); (Eggbeer et al, 2015); } \\
\text { (Carlson et al., 2010); (Garrison \& Towse, 2017); } \\
\text { (Neumann et al.., 2011); (Damberg et al., 2014); } \\
\text { (Haywood, 2010); (Kotzbauer \& Weeks, 2015); } \\
\text { (Deerberg-Wittram et al., 2017); (Porter \& Ishrak, } \\
\text { 2015); (Porter et al., 2013); (Lee, 2010); (Field \& } \\
\text { Peck, 2003); (Field \& Peck, 2003); (Patel et al., } \\
\text { 2012). }\end{array}$ \\
\hline
\end{tabular}


The following sections of the paper now describe and discuss the five GCs identified in the literature review as shown in Table 1.

\section{One: A multidisciplinary approach}

The literature describes the need for collaboration between stakeholders for the implementation of VBHC through system-sector partnerships as imperative (Deloitte, 2019; Gov UK, 2017; Nishtar, 2004). A common thread throughout are improvements to the 'Value' of healthcare provision by healthcare providers (e.g. hospitals) and associated personnel (e.g. clinical and non-clinical staff) is not established without collaboration and the involvement of all relevant stakeholders along a service user's (i.e. patient's) pathway of care (Beck et al., 2012; EIU, 2016b; Gov UK, 2016; Handke et al., 2017; Horne et al., 2019; Medtronic, 2016; VBHC Center Europe, 2019; Young et al., 2001).

It is argued that collaborative improvements in healthcare provision via a multidisciplinary approach includes the cross-pollination of perspectives from internal system stakeholders as well as those outside the system, including those from the sector (e.g. pharmaceutical and MedTech companies), charities (Gov UK, 2017; WAG, 2018), academia (VBHC Center Europe, 2019), patients and patient advocates (Horne et al., 2019). It is argued in this literature that improvements to healthcare provision can be realised by identifying meaningful outcomes. Providers aiming to improved healthcare provision, delivery and patient outcomes can do so through increased efficiency and quality of care. This is inherently complex and will require leveraging of pre-requisite multi-level knowledge, skills, experience and specialist expertise ( Gov UK, 2017; Neville, 2019; WAG, 2018. These elements are routinely utilised in areas of service provision in the system and can be used to compliment elements from sector stakeholders who offer innovation, new medicines and technologies (Gov UK: Office For Life Sciences (OLS), 2017; Neville, 2019; WAG, 2018) to support VBHC implementation through multidisciplinary collaboration.

Malik et al., 2018 demonstrate that a multi-disciplinary approach is a preferential option as opposed to a siloed approach when attempting to deliver VBHC. The study showed that a 'Physicians in the Lead' (PIL) strategy engages physicians in system organisations' processes to make them responsible for the quality and efficiency of their departments healthcare provision. This aligns the aim of delivering effective, efficient and cost-effective care with Porter's definition of 'value' in VBHC as 'patient health outcomes per dollar spent'. This study found that the holistic outcome and care delivery requires a teamworkbased strategy owing to the complementary skills and training of various healthcare professionals. This is because not all levels of specialisms and skill levels are required to deliver all outputs and outcomes throughout a service users' journey through healthcare provider or system - and therefore some tasks can be delegated. As such a new strategy was proposed, namely a "team in lead" strategy (Malik et al., 2018).

A variety of government publications (Gov UK, 2017, 2018a, 2018b; WAG, 2018) and other literature (Handke et al., 2017; Kaplan \& Babad, 2011) indicate a strong advocacy for a multi-disciplinary approach and closer system-sector alignment for more efficient implementation of VBHC initiatives. Further publications allude to the requirement for support from academic institutions (Gov UK, 2016, 2017; VBHC Center Europe, 2019; WAG, 2018); Government (EIU, 2016b; Gov UK: Office For Life Sciences (OLS), 2017; Gov UK, 2016; R. M. Kaplan \& Babad, 2011; WAG, 2018); and seekers of healthcare 
services (i.e. patients) (Beck et al., 2012; Handke et al., 2017; Medtronic, 2016; Porter et al., 2013).

It should be borne in mind that in the USA, the VBHC approach is seen as a vehicle to increase market share or drive profits through outcome improvement. Some studies describe this version of VBHC as driving performance through competition and increasing the sectors customer base (i.e. healthcare providers) (Porter \& Teisberg, 2006) which results in fragmentation and variation in the quality of care provision by healthcare providers, as these efforts do not take value at a population level into consideration (Lewis, 2019). In a publicly funded system, such as the NHS in the UK, which has the need to integrate patient care to achieve best possible outcomes and experience, it is arguably about delivering the right care, at the right time, with decisions being made based on service-user feedback, which appears to be more aligned with European and UK systems (European Commission, 2019). This approach to VBHC implementation takes the population level perspective on VBHC delivery and therefore takes patients input into a multi-disciplinary approach as intrinsic to the development and implementation of VBHC in such systems (Lewis, 2019).

However, it can be argued that a multi-disciplinary system-sector collaboration around VBHC can bring all necessary disciplines to the table and act as a vehicle for appraising new evidence from data capture during implementation of new medical technologies, pharmaceuticals and other sector products to inform an investment or dis-investment strategies according to outcomes which matter to healthcare providers and seekers.

In seeking an industry perspective, Handke et al (2017) emphasise the need for collective commitment including Government inclusion to support facilitating the transition to VBHC (Handke et al., 2017). Government policy and resource investments focused on bringing system and sector together builds confidence according to the Welsh Government (Gov UK, 2017; WAG, 2018). As system and sector partnerships require leaders from different organisations to align, the focus needs to be on achieving better outcomes for patients. There are many barriers; what is needed is greater respect, understanding and appreciation for the benefits, resources, capabilities and know-how each individual partner can contribute to establish successful initiatives such as VBHC (Martschinke \& Traut, 2016).

\section{Two: Meaningful metrics and measurements}

The challenges of determining the impact of health interventions rely on the ability to align on health outcomes that matter to patients and not to become focused on a single outcome (Porter \& Lee, 2013). It also requires the value outcome measures and costs to be analysed across the entire cycle of care (Porter \& Ishrak, 2015) which in turn requires a greater understanding of the total care cycle to design the approach at the outset.

Although healthcare systems have been gathering data for many years much of this has been focused on activity and inputs not outcome: the inability to effectively measure outcomes becomes a barrier to adoption (Neumann et al., 2011). In a study of the lack of information on relative effectiveness of different treatments in mental health, Wang et al. identified that payers are uncertain of value of investment, which may deter adoption of new innovations to address unmet need (Wang et al., 2009). Thus, determining and 
aligning on the outcome metrics is critical to achieving Value-Based Health Care (Kings Healthcare Partners (Gabriel et al., 2018)).

In the context of the current VBHC literature, it can be seen throughout that the ability to capture and analyse quality and outcomes metrics, which are considered important to healthcare providers and service users, across the patient's total (or full) cycle of care pathway is perceived to be gold standard (ICHOM, 2015; Porter \& Ishrak, 2015) . The ability to collect and subsequently analyse metrics and measurements across the full patient pathway is multi-faceted.

Firstly, collection of cost metrics and measurements across a care pathway enables the calculation of 'total cost' of treatment for a patient, or population of patients, and provide a metric for quality and outcomes provided across the pathway of care thus allowing us to gauge performance and healthcare provision efficiencies (Beck et al., 2012; Lee, 2010).

Secondly, by capture and analysis of meaningful metrics and measurement, a baseline for health outcomes and costs accumulated in providing outcomes can be provided. It should consequently be possible to benchmark current efficiencies and provide evidence for improvement or detriment on efficiencies upon implementation of new drugs, innovations or technologies into the patients cycle of care. This data collection and analysis of performance monitoring can inform business intelligence (Lee, 2010) in new VBHC collaborations between the system and sector and act as a mechanism to risk management in risk-sharing agreements and decision making. (Lee, 2010; Neumann et al., 2011). The capture and analysis of metrics and measurements would be considered important to system-sector collaborations which are engaged in risk-sharing agreements linked with 'pay for performance', or 'pay for drug outcomes' re-imbursement models (Doyle, 2011; Neumann et al., 2011).

For effective capture and analysis of meaningful metrics and measurements a robust infrastructure or technology platform will need to be embedded in the pathway for monitoring. The integration of meaningful metrics and measurements with a technology infrastructure capable of relaying desired metrics can aid in implementation of VBHC initiatives by informing consensus-based, patient centric outcome measurements (Handke et al., 2017). Organisations such as the International Consortium for Health Outcome Measurements (ICHOM) is attempting to unlock the potential of VBHC by defining Global Standard Sets of outcome measures that matter most to patients and driving adoption and reporting these measures worldwide to create better value for all stakeholders (Chapman, 2014; ICHOM, 2015).

For these reasons it is proposed that meaningful metrics and measurements are an important guiding condition for the successful implementation of VBHC through a systemsector collaboration as they can contribute to informed decision making, quality improvement and cost reduction in VBHC provision.

\section{Three: Robust infrastructure and technological platforms}

The next emerging guiding condition from the reviewed literature as essential for successful implementation of VBHC is a robust technology platform and infrastructure. 
VBHC requires a scalable platform to manage the data, to allow operationalisation, management and evaluation. Porter cites this infrastructure as a key requirement for adoption (Porter \& Ishrak, 2015). Limitations in, or the complete absence of, an adequate information system or technology to capture outcomes at scale often is identified as the barrier to success (Ford \& Hughes, 2007; Kotzbauer \& Weeks, 2015b; Neumann et al., 2011).

As part of UK Government report (Gov UK, 2016) seeking to support accelerated uptake to innovation and outcomes, an identified priority is that the digital infrastructure should enable the system to capture information on the use of innovations and associated outcomes, proposing that:

"Systems that collect electronic information on prescribing, procurement, dispensing, pricing and outcomes will be essential in enabling improvements to patient care."

(ARR, Gov UK, 2016, p.45)

As described, it appears that a robust technology platform or infrastructure which has the capability for collecting the appropriate data and information is imperative (Handke et al., 2017). The integration of data capture and analysis through a technology platform or infrastructure should be intuitive, allowing users of the technology (healthcare providers or users) to make decisions based on meaningful metrics and measurements.

Moreover, to be effective, the technology platform/infrastructure must be robust enough to be embedded within normal social and organisational practises to be effective (Hara et al., 2003). In the context of VBHC effective healthcare system infrastructures are required for closed system data sharing which could be used to ensure common understanding among partnering stakeholders (Chapman, 2014; Nishtar, 2004). The importance of a robust technology infrastructure is exemplified in the work of Kotzbauer \& Weeks (2015b), where a lack of organisational competency to upgrade technology system, constituted a barrier to the implementation of VBHC payment systems, a finding which resonates with those of others (see for example Ford \& Hughes, 2007; Neumann et al., 2011). It is apparent that the presence of a robust technology platform or infrastructure is important, as its absence is frequently cited as a barrier to value-based outcomes agreements (Ford \& Hughes, 2007; Hurh et al., 2017; Kotzbauer \& Weeks, 2015b; Porter \& Ishrak, 2015).

There is a clear link in the literature with the previous guiding condition. The ability to utilise technology platforms to capture meaningful metrics is required to support VBHC initiatives such as bundle payments across critical pathways. A further example is the importance of the monitoring of data as evidence in risk-sharing payment for outcomes agreements (Carlson et al., 2010; Hurh et al., 2017; Neumann et al., 2011). It has been identified that there is room for improvement of health data infrastructure in most countries (EIU, 2016b), and this presents a challenge to VBHC initiatives which rely on capture and analysis of metrics and measurements to make clinical decisions or payments. In light of this, it is evident that a robust technology platform or infrastructure is a key guiding condition required for successful implementation of VBHC through system-sector collaboration. 
Understanding and improving the complete pathway of diseases and their treatments is central to determining the best outcomes for patients with the resources available (Moxham, 2018). To align and collaborate successfully therefore requires both system and sector stakeholders to understand the total cycle of care.

Sackmann \& Kuchenreuther (2015) identified the need for pharmaceutical companies to demonstrate that a medicine decreases mortality or morbidity, makes the pathway more efficient or reduces the resources that a patient consumes. A demonstration of pathway efficiency or resource efficiency relies on a robust understanding of the existing pathway; this also has the benefit of further supporting the implementation of innovations in considering the skills, services and settings required to realise the full value (Kuchenreuther \& Sackman, 2015). This position is also supported by Porter:

"Outcomes should be measured for each medical condition covering the full cycle of care, including acute care, related complications, rehabilitation, and reoccurrences. It is the overall results that matter, not the outcome of an individual intervention or specialty (too narrow), or a single visit or care episode (too short)."

(Porter 2010, p2)

The ability to describe the existing care pathway, and its respective components, confers several benefits. Organisations can assess the capabilities staff require to manage care, evaluate costs of each aspect of the pathway, and consider dependencies and sequencing of care through the pathway. In relation to exploring the introduction of new innovations, organisations can evaluate how the introduction of different interventions may optimise or compound the pathway. This in turn allows the development of value-based outcomes identified through a robust understanding of the total cycle of care.

Knowledge of a total cycle of care (TCC) for a specific disease can help us understand the current status, map that care pathway and identify areas which can be improved to drive better healthcare provision for the given medical condition (Verbeek \& Lord, 2007). Furthermore, such understanding may facilitate the identification of key milestones along a patient's pathway for optimal acquisition of metrics and measurements to inform clinical or non-clinical decision making. That is to measure the cost of providing services to the service user across the whole cycle of care (Porter \& Ishrak, 2015; Verbeek \& Lord, 2007). It appears that to increase 'value' of care provision, in other words to deliver the best possible outcomes with the available resource, an understanding of, and subsequent improvement to, the completed pathway of the disease and its treatment is a requirement (Moxham, 2018). Improvements to a pathway should be informed by a holistic input from all relevant clinical and non-clinical personnel who deliver tasks relating to healthcare provision across that care pathway (Gerecke et al., 2015; Porter \& Lee, 2013; Porter et al., 2013; WAG, 2018).

By deriving the total cost of care provision across a given total patient pathway or TCC, this can be used as a baseline to trial interventions in a pathway to gauge whether there is a beneficial (or disadvantageous) result with respect to cost efficiencies and care provision. In an example of bundled payments for reimbursement, knowledge of TCC means providers can be held accountable across the full cycle of care. The ability for providers to 
compare health outcomes and costs across the entire care cycle is expected to foster improvement through competition on value, as defined by health outcomes achieved per unit cost (Akerman \& Stowell, 2015; ICHOM, 2015; Porter \& Teisberg, 2006). There is currently great interest in VBHC, mostly directed at identifying which health outcomes are appropriate to measure for a medical condition (Keel et al., 2017).

It is understood that as healthcare providers and personnel have complementary skill sets which dovetail to complement the patient (service users) journey throughout the TCC. Each staff member plays a part in the continuum of care as they possess a variety of skills and knowledge to execute tasks at the correct time and at the appropriate step in the patient pathway. Thus, it is important that each relevant stakeholder along the care pathway are consulted, otherwise there is a risk that implementation of a change perceived to be beneficial in one step of a pathway might non-beneficial results up or down-stream in the system.

\section{Five: Possessing financial flexibility}

The final guiding condition emerging strongly from the literature is the ability to flexibly deploy adequate resource, including finance, time, equipment and skilled personnel to achieve optimal healthcare provision (Patel et al., 2012).

In terms of collaborative arrangements, the design of risk-sharing agreements, and new models of reimbursement have great potential but also present significant challenge to implement, according to Neumann (Neumann et al., 2011). Collaboration requires the creation of payment systems that align financial incentives to provide greater value (Porter \& Ishrak, 2015), while dealing with barriers to success requires organisations to overcome the limited access to financial capital (Kotzbauer \& Weeks, 2015b). Value-based contracting is grounded in the premise of reducing cost by eliminating inappropriate utilization and lowering prices, sharing savings or capturing a portion of the value created through lower costs and/or increasing volume through market share gains resulting from enhanced value to the customer (Eggbeer et al., 2015).

Carlson et al (2010) identifies the potential benefits of new pricing schemes on improving health outcomes in 'real world' patients, whilst noting the significant challenges in developing these schemes due to factors such as upfront administrative burdens and dependency on robust information systems (Carlson et al., 2010). Despite the potential to alter the reimbursement and pricing landscape, these barriers may limit the long-term impact, and as such Carlson suggests further studies are required to evaluate the experiences and impact of schemes and further determine the value in healthcare spending realised. Furthermore, in exploring new models to fund innovation, both system and sector may need to make changes in their organisational accounting practices and policies. By including finance and accounting experts from the outset of partnerships, VBHC collaborations will ensure the shaping of any new approaches are compliant with local and national policy.

According to Deerberg-Wittram et al., (2017), financial and resource flexibility in the context of VBHC, is particularly important from the perspective of the system collaborating with medical technology companies. Some medical technology firms have the financial flexibility to allow investment of resource into the development of 
standardized, scalable value-based solutions, that improve outcomes-to-cost ratios in a specific domain, for example across a disease care cycle.

However, there is recognition of the requirement to co-create new business and financial models which align system and sector initiatives to provide greater value through healthcare provision (Porter \& Ishrak, 2015). It is also identified again that UK Government is encouraging system-sector contractual arrangements over a longer-term than is currently practised, but with a greater degree of flexibility (Gov UK, 2017; WAG, 2018). The proposed longer contractual agreements must be more substantive and strategic, rather than being short-term, ad-hoc agreements. The reference to flexibility in contractual arrangements is deemed important to (NHS) managers who seek flexibility in service provision from the sector (Field \& Peck, 2003). Considering this, contractual arrangements around system-sector collaborations must be properly negotiated, flexible and still offer a satisfactory deal and incentivisation for both parties (Field \& Peck, 2003).

The literature described the importance of the development of new financial models for Value-Based Pricing (VBP) and risk-sharing agreements where payers (healthcare providers) and sector stakeholders agree to link payment for drugs to health outcomes through a flexible re-imbursement models (Garrison \& Towse, 2017; Robinson et al., 2018). It is also noted that closer alignment between financial and clinical personnel is required to improve care at lower cost through development of performance-based flexible reimbursement models and a joint definition of 'Value'(Carlson et al., 2010; Garrison \& Towse, 2017).

This represents a potentially appealing reimbursement model which might aid in more efficient delivery of new medicines and products, from sector to system, targeted at better health outcomes for patients. For this to be realised finance and clinical personnel must work to agree on shared language and understanding on what they consider to be 'value' with respect to value-based pricing and contracting. This is argued to potentially improve care provision in the system and reimburse manufacturers of a new drug, technology or product in the sector through flexible performance-based re-imbursement schemes (Carlson et al., 2010; Garrison \& Towse, 2017; Lee, 2010).

Through such models and schemes, the capture of outcomes and costs associated with the care provision from the system and the opportunity for honest appraisals of new evidence from ongoing data capture (Lewis, 2019). Health outcome and cost data acquired post adoption of new drugs, technologies, innovations and products may also be used to monitor any overall changes of efficiencies across a given care pathway and could therefore inform investment or disinvestment accordingly (Garrison \& Towse, 2017; Lewis, 2019).

It is noteworthy to declare that other conditions were surfaced throughout the literature review. These included scalability (Nishtar, 2004); an embedded collaboration champion and use of their networks (Wohlin et al., 2012); high degrees of commitment and shared vision (Jacobson \& Ok Choi, 2008), trust, experience and incentives (Patel et al., 2012); time (Nilsson et al., 2017); and policy alignment (Lehoux, Miller, Daudelin, \& Denis, 2017). Although we recognise the relevance of these factors in the extant literature, further exploration was omitted from inclusion in this paper as they did not surface in more than 10 articles and therefore did not meet the criteria of the research methodology. 
To close this section, figure one is a diagrammatic representation of the five guiding conditions derived from the literature search, showing their relationship to the system and sector. The paper now concludes with the contribution of the work and recommendations for the future research agenda on VBHC.

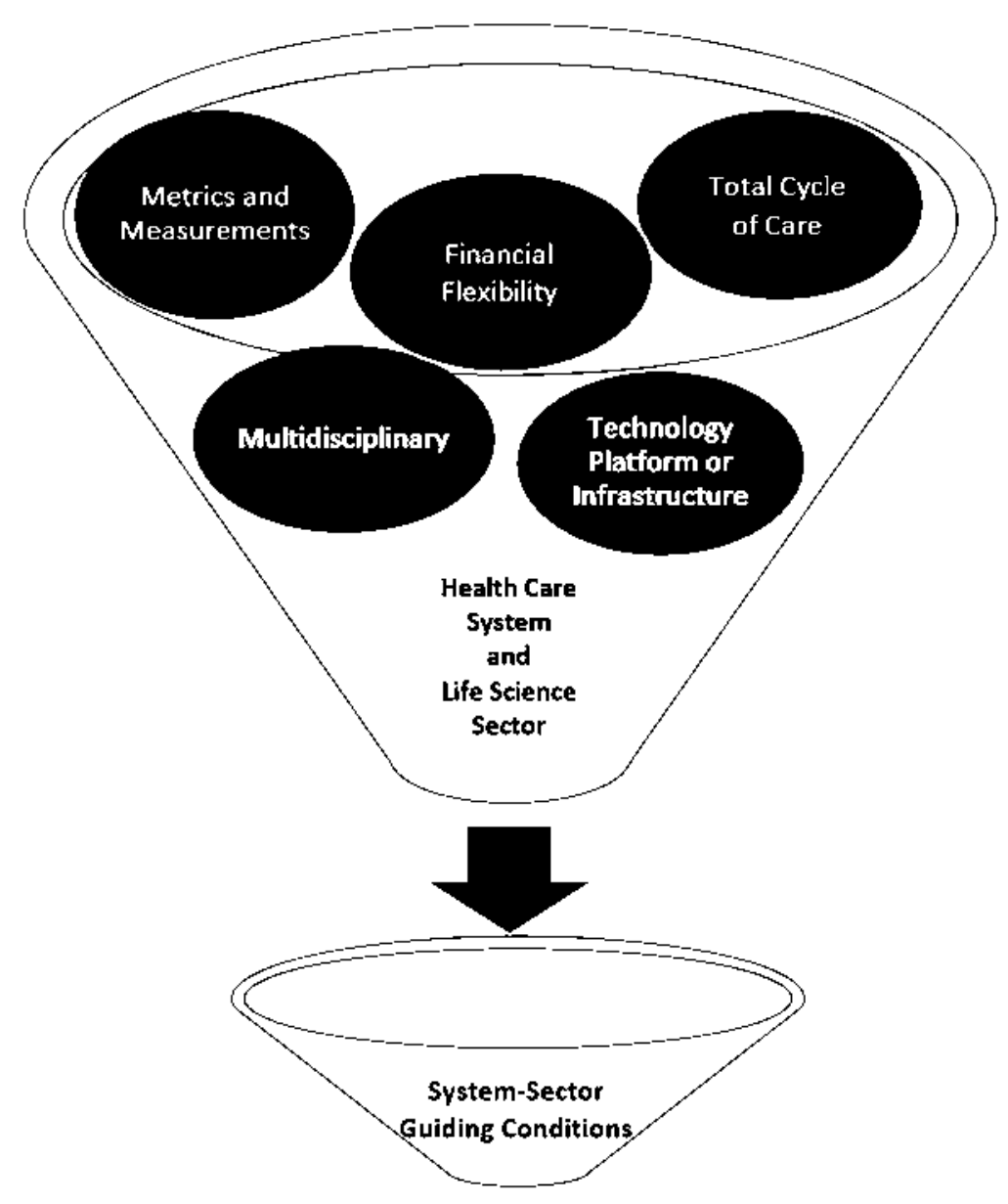

Figure 1. Guiding conditions required for system sector collaboration for implementation of VBHC.

\section{Conclusions and Further Research}

\section{The contributions of the paper}

This paper has introduced the pressures on the government-funded NHS (Crocker et al., 2009) and the concept of implementation of VBHC collaboration through the healthcare system-life science sector nexus as a mechanism of mitigation against growing challenges. The development of VBHC from initial work in the United States has been traced, but it is noted that the debate is now gaining increased traction in other geographic contexts, particularly the UK and Europe, in response to an escalating acknowledgement that current healthcare business models and funding approaches are unsustainable. 
With government and policy drive towards closer alignment of sector and system, the UK context offers a comparatively supportive policy context for collaboration (Crocker et al., 2009; Ferlie \& McGivern, 2003), as the findings of the paper suggest. It is proposed that the five GCs surfaced in this paper are fundamental for the successful implementation of VBHC through system-sector collaboration.

The strategic drivers of this increased attention were discussed, including economic factors and demographics. Potential barriers such as a lack of societal trust of corporate involvement in the UK NHS were briefly considered, but the main focus of this paper is the current lack of large-scale operational collaboration between the healthcare industry and the healthcare systems, outside of the research environment. It is evident from the review underpinning this paper that there are few examples of collaborations by an industry and healthcare system partner that have been proven to have achieved the balance of service delivery optimisation with constrained resources and adherence to performance measures requires in one region and adopted across a healthcare system(s) (Chahal \& Eldabi, 2011).

It is noted that Porter and Lee have proposed components of a strategy "...for moving to a high-value healthcare delivery system" (Porter \& Lee, 2013, p. 52). However, while their proposition should be noted, the guiding conditions set out here have drawn insights from a broad range of literature incorporating research from contexts outside of the US. Moreover, the authors concur with Gray, who emphasises "...the important difference in the use of the term value in the American literature" (Gray, 2017b, p. 1).

The conclusions from this exploratory work shows that while an accepted model of collaboration does not yet exist, the literature suggests determinants that can enable successful collaborations. It is acknowledged that the healthcare landscape is complex and that these five guiding conditions represent an abstraction of that reality. However, as a framework to help make sense of this complexity it is proposed that they offer a starting point for analysis and a potentially useful guide to further research.

It is argued that this paper has made a constructive contribution to the field by further insight beyond the valuable work undertaken in the United States, to include more research from the United Kingdom and Europe. In this way it is hoped to extend our understanding of VBHC and in particular the way the notion of 'value' is used in differing contexts.

More broadly, the review of the literature convinces that a collaborative approach is crucial for the necessary paradigm shift in the way that healthcare funding is approached and the dominant business models in the healthcare industry. Ultimately the aim of this research agenda is to contribute to practice and policy; to influence these for the betterment of patient care in the complex context imposed by the strategic drivers discussed in the introductory section. However, this depends on the execution of a coherent and focused research agenda, and it is to this final contribution of the paper to which we now turn. 


\section{Recommendations for future research}

While understanding of VBHC is growing, it remains comparatively under-researched as an alternative paradigm for healthcare. The context is self-evidently complex, and therefore one of the key objectives of this paper is to propose a coherent programme of further research on VBHC.

The next stage of the research agenda requires a focus on the empirical assessment of the proposed guiding conditions discussed in this paper. In parallel, the analysis of the literature on VBHC needs to remain an ongoing project, in light of the growing body of research and the increasing demand for alternative approaches from those engaged in healthcare from a practical perspective.

The literature-derived GCs should now be evaluated empirically for their perceived practical importance to key participants, or potential participants in system-sector collaboration toward VBHC.

Continuing exploration to build on the work of this paper should employ multiple methods of data gathering and analysis. Initially it is proposed that in-depth interviews with key respondents are used to obtain rich data on perceptions of the significance of the guiding conditions. This data could then be analysed using techniques such as content analysis and interpretive structural modelling (ISM) to help articulate the complexity of the relationships in research context more clearly. Further larger-scale studies employing elements of quantitative analysis should follow this initial 'theory building' phase, which will allow well founded proposals for practice to be made. The future contribution to practice should include recommendations on the role of government and policy on facilitating the conditions for collaboration in VBHC

The empirical evaluation of the five guiding conditions may confirm these themes from the literature. However, it will be important to remain sensitive to further themes that may emerge from the data such as those previously highlighted, but omitted from the scope for further exploration, in this study. In addition, it may be possible to begin to build increased understanding of the relative importance of the guiding conditions, and how the relationships between them may be explored.

Ultimately, the objective of the research agenda should be the development of a systemsector collaborative model to inform alignment of industry, the NHS and academia to innovate in pursuit of improved patient and public outcomes. Here, academia can arguably be utilised as an un-biased broker for research and knowledge transfer. Following the elucidation of a five importance guiding conditions, the commissioning of further largerscale studies through engagement with system and sector stakeholders should be sought to provide an evaluation for the current working model and identify barriers/challenges and opportunities for improvement. Thus, describing an enhanced model/framework for improving the current and future healthcare-industrial collaborations through the lens of VBHC.

As stated earlier, it is acknowledged that the list of five guiding conditions could be criticised as being overly reductive. It is axiomatic that these will be interlinked in complex ways. For this reason, one strand of conceptual development should be to develop an overarching perspective that allows for an understanding of this complexity while offering shared principles for action across the system-sector collaborative ecosystem. It is 
suggested tentatively that the concept of 'strategic agility' (see for example Doz and Kosonen, 2010) could offer a useful lens through which to consider a shared approach to system-sector collaboration. Essentially, organisations that consider themselves strategically agility retain the ability to continuously adjust strategic direction and develop innovative ways to create value while retaining an overall direction or mission (Weber \& Tarba, 2014). The underlying 'meta-capabilities' demanded by strategic agility bear strong resemblance to many of the characteristics of the guiding conditions identified here. While this is a concept that has been applied largely to the private sector, it has already been used to examine strategic alliances and may offer a useful holistic construct for multistakeholder collaborations.

In summary, whichever lens is employed to examine the VBHC landscape, the complexity of the collaborative ecosystem needs to be acknowledged. Despite this, it is proposed here that the five guiding conditions revealed by this evaluation of the developing literature on VBHC offer a practical and constructive framework that has the potential to inform both policy and further theoretical development.

\section{References}

Akerman, C., \& Stowell, C. (2015). Measuring outcomes: the key to Value-based health care. Harv Bus Webinar .

Aneurin Bevan University Health Board. (2019). Value Based Healthcare: Learning from practice.

AstraZeneca. (2018). AstraZeneca Collaboration with Leeds Teaching Hospitals NHS Trust.

Bacon, E., Williams, M. D., \& Davies, G. H. (2019). Recipes for success: Conditions for knowledge transfer across open innovation ecosystems. International Journal of Information Management, 49, 377-387. https://doi.org/10.1016/j.ijinfomgt.2019.07.012

Beck, E., Craing, A., Beeson, J., Bourn, S., Goodloe, J., Moy, H. P., ... White, L. (2012). Mobile Integrated Healthcare Practice : A Healthcare Delivery Strategy to Improve Access, Outcomes, and Value.

Berwick, D. M., \& Hackbarth, A. D. (2012). Eliminating Waste in US Health Care. JAMA, 307(14), 1513-1516. https://doi.org/10.1001/jama.2012.362

Carlson, J. J., Sullivan, S. D., Garrison, L. P., Neumann, P. J., \& Veenstra, D. L. (2010). Linking payment to health outcomes: A taxonomy and examination of performancebased reimbursement schemes between healthcare payers and manufacturers. Health Policy, 96(3), 179-190. https://doi.org/10.1016/j.healthpol.2010.02.005

Chahal, K., \& Eldabi, T. (2011). Hybrid simulation and modes of governance in UK healthcare. Transforming Government: People, Process and Policy, 5(2), 143-154. https://doi.org/10.1108/17506161111131177

Chapman, A. (2014). The Impact of Reliance on Private Sector Health Services on the Right to Health. Health and Human Rights Journal , 16(1).

Charlesworth, A., Johnson, P., Firth, Z., Gershlick, B., Watt, T., Kelly, E., ... Zaranko, B. (2018). Securing the future: funding health and social care to the 2030. Retrieved from http://www.ifs.org.uk

Charlesworth, Anita, Charlesworth, A., Watt, T., \& Johnson, P. (2018). Securing the future : funding health and social care to the 2030. In Institute of Fiscal Studies.

Collins, B. (2018). Adoption and spread of innovation in the NHS. Retrieved October 4, 2019, from The Kings Trust website: 
https://www.kingsfund.org.uk/publications/innovation-nhs

Crocker, T., Johnson, O., \& King, S. (2009). The suitability of care pathways for integrating processes and information systems in healthcare. Transforming

Government: People, Process and Policy, 3(3), 289-301. https://doi.org/10.1108/17506160910979379

Damberg, C. L., Sorbero, M. E., Lovejoy, S. L., Martsolf, G. R., Raaen, L., \& Mandel, D. (2014). Measuring Success in Health Care Value-Based Purchasing Programs: Findings from an Environmental Scan, Literature Review, and Expert Panel Discussions. Rand Health Quarterly, 4(3), 9. Retrieved from https://www.ncbi.nlm.nih.gov/pubmed/28083347

Deerberg-Wittram, M., Lüdtke, L., Lavoie, B., Schroer, D., \& Gerecke, G. (2017). Why Every Medtech Company Needs a Value-Based Strategy. BCG. Retrieved from https://www.bcg.com/publications/2017/health-care-why-every-medtech-companyneeds-value-based-strategy.aspx

Deloitte. (2018). The evolution of smart health care. Global Health Care Outlook, 1-31. Retrieved from https://www2.deloitte.com/content/dam/Deloitte/global/Documents/Life-SciencesHealth-Care/gx-lshc-hc-outlook-2018.pdf

Deloitte. (2019). Patient access to innovative medicines in Europe: A collaborative and value based approach. (January), 40. Retrieved from https://www2.deloitte.com/content/dam/Deloitte/uk/Documents/life-sciences-healthcare/deloitte-uk-patient-access-to-innovative-medicine-in-europe.pdf

Doyle, J. (2011). The effect of comparative effectiveness research on drug development innovation: a $360^{\circ}$ value appraisal. Dove Press, 1, 27-34. https://doi.org/https://doi.org/10.2147/CER.S15478

Eggbeer, B., Sears, K., \& Homer, K. (2015). Finding the 'sweet spot' in value-based contracts. Healthcare Financial Management, 69(8), 48-57.

EIU. (2016a). Healthcare and Pharmaceuticals. In The Economist Intelligence Unit.

EIU. (2016b). Value-based healthcare: A global assessment. The Economist Intelligence Unit: Findings and Methodology., 1-31. Retrieved from http://vbhcglobalassessment.eiu.com/wpcontent/uploads/sites/27/2016/09/EIU_Medtronic_Findings-and-Methodology.pdf

European Commission. (2019). Defining Value In "Value-Based Healthcare" : Expert Panel on effective ways of investing in Health (EXPH). https://doi.org/10.2875/872343

EXPH. (2019). Expert panel on effective ways of investing in health. Opinion on Defining value in "value-based healthcare." In European Commission. https://doi.org/10.2875/35471

Ferlie, E., \& McGivern, G. (2003). Relationships between health care organisations: a critical overview of the literature and a research agenda. (January 2003). Retrieved from

http://scholar.google.com/scholar?q=related:IyWWwAMbp3gJ:scholar.google.com/ $\& \mathrm{hl}=\mathrm{en} \&$ num $=30 \& a \mathrm{~s} \_\mathrm{sdt}=0,5$

Field, J. E., \& Peck, E. (2003). Public-private partnerships in healthcare: the managers' perspective. Health \& Social Care in the Community, 11(6), 494-501. https://doi.org/10.1046/j.1365-2524.2003.00455.x

Ford, E. W., \& Hughes, J. A. (2007). A Collaborative Product Commerce Approach to Value-based Health Plan Purchasing. Supply Chain Management: An International Journal., 12(1), 32-41.

Gabriel, L., Fellow, D., Casey, J., Delivery, D. P., Palmer, M. C., Outcomes, P., ... John, 
P. (2018). Value Based Healthcare analysis of joint replacement surgery for primary hip osteoarthritis Why take on a Value Based Healthcare transformation Traditional PROMS vs patient-centred outcomes Calculating value : understanding outcomes that matter to patient.

Garrison, L. P., \& Towse, A. (2017). Value-Based Pricing and Reimbursement in Personalised Healthcare: Introduction to the Basic Health Economics. Journal of Personalized Medicine, 7(3), 10. https://doi.org/10.3390/jpm7030010

Gerecke, G., Clawson, J., \& Verboben, Y. (2015). Procurement: The Unexpected Driver of Value-Based Health Care. BCG Report.

Gov UK: Office For Life Sciences (OLS). (2017). Strength and Opportunity 2017: The landscape of the medical technology and biopharmaceutical sectors in the UK.

Gov UK. (2016). Accelerated Access Review: Final Report: Review of innovative medicines and medical technologies. Retrieved from

https://www.gov.uk/government/uploads/system/uploads/attachment_data/file/5650 72/AAR_final.pdf

Gov UK. (2017). Life sciences: Industrial Strategy. Retrieved from https://assets.publishing.service.gov.uk/government/uploads/system/uploads/attach ment_data/file/650447/LifeSciencesIndustrialStrategy_acc2.pdf

Gov UK. (2018a). Industrial Strategy: Life Sciences Sector Deal 2.

Gov UK. (2018b). New Life Sciences Sector Deal opens doors to transform treatments and save lives. Retrieved January 29, 2020, from https://www.gov.uk/government/speeches/new-life-sciences-sector-deal-opensdoors-to-transform-treatments-and-save-lives

Gray, M. (2017). Value based healthcare. BMJ, j437. https://doi.org/10.1136/bmj.j437

Handke, B., Gaffney, J., \& Oberoi, N. (2017). Value-Based Healthcare: An Industry Perspective. Vein Magazine.

Hara, N., Solomon, P., Kim, S.-L., \& Sonnenwald, D. H. (2003). An emerging view of scientific collaboration: Scientists' perspectives on collaboration and factors that impact collaboration. Journal of the American Society for Information Science and Technology, 54(10), 952-965. https://doi.org/10.1002/asi.10291

Hardin, L., Kilian, A., \& Murphy, E. (2017). Bundled Payments for Care Improvement: Preparing for the Medical Diagnosis-Related Groups. The Journal of Nursing Administration, 47(6), 313-319. https://doi.org/10.1097/NNA.0000000000000492

Haywood, T. (2010). The cost of confusion: healthcare reform and value-based purchasing. Healthcare Financial Management, 64(10), 44-49.

Horne, F., Katz, G., \& Seidman, G. (2019). Four lessons for a successful switch to valuebased healthcare. Retrieved from https://www.weforum.org/agenda/2019/03/fourlessons-for-successful-healthcare-transformation/

Hu, P., Chau, P., \& Sheng, O. (2000). Investigation of Factors Affecting Healthcare Organizations' Adoption of Telemedicine Technology. https://doi.org/10.1109/HICSS.2000.926799

Hurh, J., Ko, Y.-H., \& Lee, S.-S. (2017). Value-based healthcare: Prerequisites and suggestions for full-fledged implementation in the Republic of Korea. Journal of Korean Medical Association, 60, 826. https://doi.org/10.5124/jkma.2017.60.10.826

ICHOM. (2015). What Matters Most: Patient Outcomes and the Transformation of Health Care. International Consortium for Health Outcomes Measurement.

Jacobson, C., \& Ok Choi, S. (2008). Success factors: public works and public-private partnerships. International Journal of Public Sector Management, 21(6), 637-657. https://doi.org/10.1108/09513550810896514

Jönsson, B. (2009). Ten arguments for a societal perspective in the economic evaluation 
of medical innovations. The European Journal of Health Economics, 10(4), 357359. https://doi.org/10.1007/s10198-009-0173-2

Kaplan, R. M., \& Babad, Y. M. (2011). Balancing influence between actors in healthcare decision making. BMC Health Services Research, 11(1), 85. https://doi.org/10.1186/1472-6963-11-85

Kaplan, R., \& Porter, M. (2011). How to solve the cost crisis in health care. Harvard Business Reviews, 54, 56-61.

Kavanagh, K. T., Cimiotti, J. P., Abusalem, S., \& Coty, M.-B. (2012). Moving healthcare quality forward with nursing-sensitive value-based purchasing. Journal of Nursing Scholarship : An Official Publication of Sigma Theta Tau International Honor Society of Nursing, 44(4), 385-395. https://doi.org/10.1111/j.15475069.2012.01469.x

Keel, G., Savage, C., Rafiq, M., \& Mazzocato, P. (2017). Time-driven activity-based costing in health care: A systematic review of the literature. Health Policy, 121(7), 755-763. https://doi.org/https://doi.org/10.1016/j.healthpol.2017.04.013

Kotzbauer, G., \& Weeks, W. (2015a). Developing the organizational competencies needed in value-based payment systems. Healthcare Financial Management, 69(7), 76-77.

Kotzbauer, G., \& Weeks, W. B. (2015b). Developing the organizational competencies needed in value-based payment systems. Healthcare Financial Management, 67(7), 76-77. Retrieved from https://search.proquest.com/docview/1699223103?accountid=14680

Kuchenreuther, M. J., \& Sackman, J. E. (2015). Value-Based Healthcare in the: United Kingdom. Pharmaceutical Technology, 39(1).

Lee, T. H. (2010). Putting the Value Framework to Work. New England Journal of Medicine, 363(26), 2481-2483. https://doi.org/10.1056/NEJMp1013111

Leemore S. Dafny, Ph.D., Christopher J. Ody, Ph.D., and Matthew A. Schmitt, P. D. (2016). Undermining Value-Based Purchasing — Lessons from the Pharmaceutical Industry. New England Journal of Medicine, 1-3.

Lehoux, P., Miller, F. A., Daudelin, G., \& Denis, J.-L. (2017). Providing Value to New Health Technology: The Early Contribution of Entrepreneurs, Investors, and Regulatory Agencies. International Journal of Health Policy and Management, 6(9), 509-518. https://doi.org/10.15171/ijhpm.2017.11

Lewis, S. (2019). Value-based healthcare - meeting the evolving needs. Australian Health Review, 43(5), 485. https://doi.org/http://dx.doi.org/10.1071/AHv43n5_ED

Malik, R. F., Hilders, C. G. J. M., \& Scheele, F. (2018). Do 'physicians in the lead' support a holistic healthcare delivery approach? A qualitative analysis of stakeholders' perspectives. BMJ Open, 8(7), e020739. https://doi.org/10.1136/bmjopen-2017-020739

Martschinke, B., \& Traut, A. (2016). Early Benefit Assessment Of Drugs And The Value-Based Healthcare Concept - A Qualitative Inquiry Within The Pharmaceutical Industry. Value in Health, 19(7), A448. https://doi.org/10.1016/j.jval.2016.09.589

Medtronic. (2016). Medtronic Focus on Value-based Healthcare Increases Worldwide. Key Event Takeaways, 1-2.

Miller, D. (2012). Value-Based Pricing: Examples of Healthcare System Reforms from the UK and US and Implications for Industry. Pharmaceutical Medicine, 26(4), 217-222. https://doi.org/DOI: 10.2165/11633860-000000000-00000,

Mills, M., \& Kanavos, P. (2019). Do pharmaceutical budgets deliver financial sustainability in healthcare? Evidence from Europe. Health Policy, 168(19). 
https://doi.org/doi: 10.1016/j.healthpol.2019.12.002.

Moxham, J. (2018). The Vital 5. Retrieved October 3, 2019, from The Kings Trust website: https://www.kingshealthpartners.org/latest/1954-the-vital-5

Neumann, P. J., Chambers, J. D., Simon, F., \& Meckley, L. M. (2011). Risk-Sharing Arrangements That Link Payment For Drugs To Health Outcomes Are Proving Hard To Implement. Health Affairs, 30(12), 2329-2337. https://doi.org/10.1377/hlthaff.2010.1147

Neville, S. (2019). NHS and Life Science Sector Failing to Work Together. Financial Times.

Nilsson, K., Bååthe, F., Andersson, A. E., Wikström, E., \& Sandoff, M. (2017).

Experiences from implementing value-based healthcare at a Swedish University Hospital - a longitudinal interview study. BMC Health Services Research, 17(1), 169. https://doi.org/10.1186/s12913-017-2104-8

Nishtar, S. (2004). Public - private "partnerships" in health - a global call to action. Health Research Policy and Systems, 2(1), 5. https://doi.org/10.1186/1478-4505-2-5

OECD. (2017). Tackling Wasteful Spending on Health. https://doi.org/https://doi.org/10.1787/9789264266414-en.

Patel, H., Pettitt, M., \& Wilson, J. R. (2012). Factors of collaborative working: A framework for a collaboration model. Applied Ergonomics, 43(1), 1-26. https://doi.org/https://doi.org/10.1016/j.apergo.2011.04.009

Pilemalm, S., Lindgren, I., \& Ramsell, E. (2016). Emerging forms of inter-organizational and cross-sector collaborations in e-government initiatives: Implications for participative development of information systems. Transforming Government: People, Process and Policy, 10(4), 605-636. https://doi.org/10.1108/TG-12-20150055

Porter, M. E., \& Ishrak, O. (2015). The State of Adoption in Value-Based Health Care. New England Journal of Medicine Report, 1-9.

Porter, M. E., \& Lee, T. H. (2013). The Strategy That Will Fix Health Care. Harvard Business Review.

Porter, M. E., Pabo, E. A., \& Lee, T. H. (2013). Redesigning Primary Care: A Strategic Vision To Improve Value By Organizing Around Patients' Needs. Health Affairs, 32(3), 516-525. https://doi.org/10.1377/hlthaff.2012.0961

Porter, M. E., \& Teisberg, E. (2006). Redefining Health Care: Creating Value-Based Competition on Results. Harvard Business School Press.

Robinson, J. C., Howell, S., \& Pearson, S. D. (2018). Value-Based Pricing and Patient Access for Specialty Drugs. JAMA, 319(21), 2169-2170. https://doi.org/10.1001/jama.2018.5367

TheKingsFund. (2019). The NHS long-term plan explained. Retrieved October 3, 2019, from https://www.kingsfund.org.uk/publications/nhs-long-term-plan-explained

VBHC Center Europe. (2019). Pursuing the next steps of VBHC implementation: from good to great patient value Looking back to move forward. Retrieved from www.thedecisioninstitute.org

Verbeek, X., \& Lord, W. (2007). The care cycle: an overview. Medicamundi, 51(1), 4047.

WAG. (2018). Welsh Government | A Healthier Wales: our Plan for Health and Social Care. Retrieved from https://gweddill.gov.wales/docs/dhss/publications/180608healthier-walesmainen.pdf\%0Ahttps:/gov.wales/topics/health/publications/healthierwales/?lang=en

Wang, P. S., Ulbricht, C. M., \& Schoenbaum, M. (2009). Improving Mental Health 
Treatments Through Comparative Effectiveness Research. Health Affairs, 28(3), 783-791. https://doi.org/10.1377/hlthaff.28.3.783

WHO. (2009). WHO Guidelines on Hand Hygiene in Health Care: First Global Patient Safety Challenge Clean Care Is Safer Care. Geneva: World Health Organization. Retrieved January 27, 2020, from https://www.ncbi.nlm.nih.gov/books/NBK144006/

Wohlin, C., Aurum, A., Angelis, L., Phillips, L., Dittrich, Y., Gorschek, T., Winter, J. (2012). The Success Factors Powering Industry-Academia Collaboration. IEEE Software, 29(2), 67-73. https://doi.org/10.1109/MS.2011.92

Young, D., Barrett, D., Kenagy, J., Pinakiewicz, D., \& McCarthy, S. (2001). ValueBased Partnering in Healthcare: A Framework for Analysis//Practitioner application. Journal of Healthcare Management / American College of Healthcare Executives, 46, 112-132; discussion 133. https://doi.org/10.1097/00115514-200103000-00007

Zelmer, J. (2018). Identifying the Most Promising Opportunities for Value-Based Healthcare: Design Day Strategic Outcomes Summary. 